\title{
Assessment of Glutamate Transporter GLAST (EAATI)- Deficient Mice for Phenotypes Relevant to the Negative and Executive/Cognitive Symptoms of Schizophrenia
}

\author{
Rose-Marie Karlsson*, I,2, Kohichi Tanaka ${ }^{3}$, Lisa M Saksida ${ }^{4,5}$, Timothy J Bussey ${ }^{4,5}$, Markus Heilig ${ }^{1,2}$ and \\ Andrew Holmes 6 \\ 'Laboratory of Clinical and Translational Studies, National Institute on Alcohol Abuse and Alcoholism, NIH, Bethesda, MD, USA; ${ }^{2}$ Department of \\ Clinical Neuroscience, Karolinska Institute, Stockholm, Sweden; ${ }^{3}$ Laboratory of Molecular Neuroscience, School of Biomedical Science and Medical \\ Research Institute, Tokyo Medical and Dental University, Tokyo, Japan; ${ }^{4}$ Department of Experimental Psychology, University of Cambridge, \\ Cambridge, UK; ${ }^{5}$ The Medical Research Council and Wellcome Trust Behavioral and Clinical Neuroscience Institute, Cambridge, UK; ${ }^{5}$ Section on \\ Behavioral Science and Genetics, Laboratory for Integrative Neuroscience, National Institute on Alcoholism and Alcohol Abuse, NIH, Rockville, \\ MD, USA
}

\begin{abstract}
Glutamatergic dysfunction is increasingly implicated in the pathophysiology of schizophrenia. Current models postulate that dysfunction of glutamate and its receptors underlie many of the symptoms in this disease. However, the mechanisms involved are not well understood. Although elucidating the role for glutamate transporters in the disease has been limited by the absence of pharmacological tools that selectively target the transporter, we recently showed that glial glutamate and aspartate transporter (GLAST; excitatory aminoacid transporter I) mutant mice exhibit abnormalities on behavioral measures thought to model the positive symptoms of schizophrenia, some of which were rescued by treatment with either haloperidol or the mGlu2/3 agonist, LY379268 the mGlu2/3 agonist, LY379268. To further determine the role of GLAST in schizophrenia-related behaviors we tested GLAST mutant mice on a series of behavioral paradigms associated with the negative (social withdrawal, anhedonia), sensorimotor gating (prepulse inhibition of startle), and executive/ cognitive (discrimination learning, extinction) symptoms of schizophrenia. GLAST knockout (KO) mice showed poor nesting behavior and abnormal sociability, whereas $\mathrm{KO}$ and heterozygous (HET) both demonstrated lesser preference for a novel social stimulus compared to wild-type littermate controls. GLAST KO, but not HET, had a significantly reduced acoustic startle response, but no significant deficit in prepulse inhibition of startle. GLAST KO and HET showed normal sucrose preference. In an instrumental visual discrimination task, $\mathrm{KO}$ showed impaired learning. By contrast, acquisition and extinction of a simple instrumental response was normal. The mGlu2/3 agonist, LY379268, failed to rescue the discrimination impairment in KO mice. These findings demonstrate that gene deletion of GLAST produces select phenotypic abnormalities related to the negative and cognitive symptoms of schizophrenia. Neuropsychopharmacology (2009) 34, I578-1589; doi:I0.1038/npp.2008.215; published online I0 December 2008
\end{abstract}

Keywords: glutamate; schizophrenia; cognition; prepulse inhibition; social withdrawal; anhedonia

\section{INTRODUCTION}

Glutamatergic dysfunction is implicated in the pathophysiology of various neuropsychiatric conditions, including schizophrenia (Coyle, 2006; Harrison and Weinberger, 2005; Krystal et al, 2002; Lewis and Gonzalez-Burgos, 2006; Olney et al, 1999). $N$-methyl-D-aspartate receptor (NMDAR) antagonists such as ketamine and phencyclidine (PCP)

*Correspondence: R-M Karlsson, Laboratory of Clinical and Translational Studies, National Institute on Alcohol Abuse and Alcoholism, $\mathrm{NIH}$, I0-Center Drive, IO Room IE-5330, Bethesda, MD 20892, USA, Tel: + | 30 | 443 2674, Fax: + | 301480 1952,

E-mail: karlssonr@mail.nih.gov

Received 2 October 2008; revised 5 November 2008; accepted 5 November 2008 mimic the symptoms of schizophrenia in healthy subjects and provoke relapse in schizophrenics (Adler et al, 1999; Krystal et al, 1994; Malhotra et al, 1997; Newcomer et al, 1999). In rodents, NMDAR antagonists produce a range of 'schizophrenia-related' behavioral abnormalities (Arguello and Gogos, 2006; Powell and Miyakawa, 2006). These effects are posited to relate to antagonism of NMDAR on GABAergic interneurons, in prefrontal cortex (PFC), leading to disinhibition of glutamate release and excessive neuronal excitability (Homayoun and Moghaddam, 2007; Kargieman et al, 2007). Possibly in support of this model is the recent demonstration of the antipsychotic efficacy of group II mGlu receptor (mGlu2/3) agonists (Patil et al, 2007) that negatively modulate glutamate release and normalize NMDAR antagonist-induced increases in 
PFC glutamate (Conn and Pin, 1997; Moghaddam and Adams, 1998).

Abnormalities in regulatory components of the glutamate system could be significant risk factors for schizophrenia. Glutamatergic signaling is regulated by a family of glutamate transporters: glial glutamate and aspartate transporter (GLAST; excitatory amino-acid transporter 1), glial glutamate transporter-1 (GLT-1; excitatory amino-acid transporter 2), excitatory amino-acid carrier 1 (EAAC1; excitatory amino-acid transporter 3 ), and excitatory aminoacid transporter 4 (EAAT4). In rodent, GLAST is expressed on astrocytes mainly in cerebellum, but also in forebrain regions including cerebral cortex and hippocampus (Torres and Amara, 2007). Postmortem studies revealed no changes in expression of glutamate transporter GLAST in the striatum (McCullumsmith and Meador-Woodruff, 2002), but elevated expression in thalamus (Smith et al, 2001), dorsolateral PFC and anterior cingulate cortex (Bauer et al, 2008), however the latter study also showed a decrease in protein levels in these regions. An association study found no polymorphism in the gene encoding human GLAST $(S L C 1 A 3)$ in a Japanese population with schizophrenia (Deng et al, 2007) however a more recent study found increased incidence of a rare genetic variant in the human gene encoding GLAST in schizophrenics (Walsh et al, 2008). In addition, we showed that GLAST knockout (KO) mice exhibit exaggerated locomotor activity in response to a novel environment or administration of the NMDA antagonist, MK-801 (Karlsson et al, 2008). This noveltyinduced locomotor hyperactivity was effectively normalized by treatment with either the prototypical antipsychotic haloperidol or the novel putative antipsychotic mGlu2/3 receptor agonist, LY379268 (Karlsson et al, 2008).

Our previous work demonstrated that GLAST KO exhibited phenotypic abnormalities thought to model certain positive symptoms of schizophrenia (psychomotor agitation and supersensitivty to psychotomimetics). The aim of this study was to evaluate phenotypic end points considered relevant to negative and attentional/cognitive domains of schizophrenia in GLAST KO. Prominent among negative symptoms is abnormal social behavior and social withdrawal (American Psychiatric Association, 2000). Attentional/cognitive changes in schizophrenia include impaired sensorimotor gating and poor performance on various measures of memory and executive function (American Psychiatric Association, 2000). On the basis of suggestions for how these symptoms might be assayed in rodents (Arguello and Gogos, 2006; Powell and Miyakawa, 2006), we examined GLAST heterozygous (HET) and KO for social and nesting behaviors anhedonia, sensorimotor gating, instrumental learning and extinction, and discrimination and reversal learning.

\section{MATERIALS AND METHODS}

\section{Subjects}

GLAST KO were generated as previously described using '129/Sv' (precise substrain not specified) embryonic stem cells injected into C57BL/6 blastocysts (Watase et al, 1998) and backcrossed into C57BL/6 for an undetermined number of generations. To avoid potential phenotypic abnormalities resulting from potential genotypic differences in maternal behavior and early life environment (Millstein and Holmes, 2007), KO, HET, and wild-type (WT) mice were all generated from HET $\times$ HET matings. A previous study has reported offspring with a Mendelian distribution (Watase et al, 1998). Our HET mating paradigm resulted in $36 \% \mathrm{WT}$, $50 \% \mathrm{HET}$, and $14 \% \mathrm{KO}$. At weaning, mice were housed in groups of 1-4 per cage in a temperature- and humiditycontrolled vivarium, under 12-h light/dark cycle (lights on 0600 hours), with ad libitum access to food and water, testing was conducted at the age of 2-6 months. Males and females were used. The number of mice used in each experiment is given in the figure legends. The experimenter remained blind to genotype during testing; mice were identified by tail-tattoos or subcutaneously implanted microchips (AVID MicroChip ID, Folsom, LA, USA). Where appropriate, mice were acclimated to the test room for $1 \mathrm{~h}$ before testing. All experimental procedures were approved by the National Institute of Alcohol Abuse and Alcoholism Animal Care and Use Committee and followed the NIH guidelines Using Animals in Intramural Research and from the Institutional Animal Care and Use Committee of Tokyo Medical and Dental University and the Tokyo Metropolitan Institute of Neuroscience.

\section{Functional Observation Battery}

GLAST HET and KO were first evaluated for empty cage behaviors, physical health, sensory, and neurological functions (Boyce-Rustay and Holmes, 2006; Crawley and Paylor, 1997; as procedure is same as previously described in our laboratory, see Supplementary Material and Methods for details).

\section{Novelty-Induced Locomotor Activity}

We first sought to replicate our recent finding that GLAST KO showed locomotor hyperactivity in a novel open field (Karlsson et al, 2008; procedure same as previously described in our laboratory: see Supplementary Material and Methods for details).

\section{Sociability and Social Novelty Preference}

Next, to test for social abnormalities in GLAST KO, we assessed sociability and social novelty preference based on methods previously described (Crawley, 2007; McFarlane et al, 2008). The apparatus was a white Plexiglas square arena $(40 \times 40 \times 35 \mathrm{~cm}, 10 \mathrm{~lx})$ containing two wire-bar cups (Galaxy Cup; Spectrum Diversified Designs Inc., Streetsboro, $\mathrm{OH}$ ) placed on either side of the arena. To reduce novelty-related locomotor hyperactivity in GLAST KO, the sides of the arena containing the cages were covered by black Plexiglas partitions $(38 \times 13.5 \times 14 \mathrm{~cm})$, and all subjects were habituated to the arena for $20 \mathrm{~min} 24 \mathrm{~h}$, and then again $20 \mathrm{~min}$, before test. To test sociability, an unfamiliar male C57BL6/J mouse was placed in one cage (the other cage remained empty (inanimate stimulus)) and the subject was manually observed for time sniffing (snout in physical contact with the wire bar) either cage over a 10 min test session using the Hindsight software program (Scientific Programming Services, Wokingham, UK). A 
disposable plastic cup was placed over the cages to prevent the subject from climbing on top. To test social novelty preference, another unfamiliar male C57BL6/J mouse was placed in the empty cage and sniffing of the cages containing the now-familiar $v s$ the novel stimulus mouse measured over a $10 \mathrm{~min}$ test session. The effect of genotype and stimulus were analyzed (separately for the sociability and social preferences tests) by ANOVA, with withinsubjects analysis for stimulus, followed by Newman-Keuls post hoc analysis.

\section{Free Social Interaction}

As a second test for social behavior, free social interaction between mice in a dyadic encounter was measured during a didactic encounter with a novel conspecific (Wiedholz et al, 2008; procedure same as previously described in our laboratory: see Supplementary Material and Methods for details).

\section{Hidden Food Retrieval Test for Olfaction}

A food burying test was conducted as a control test for potential deficits in general olfactory function that could potentially confound measurement of social behavior (Crawley, 2007). To reduce neohypophagia, mice were first exposed to Teddy Grahams ${ }^{\circledR}$ Chocolate (Kraft Foods) in their home cage 2 days before testing. Following 15-17 h food deprivation the mouse was placed in a clean cage containing $3 \mathrm{~cm}$ deep bedding (Eighth-inch bed-o'cobs; The Andersons Inc., Maumee, OH). After a 5 min habituation period, the mouse was removed, one Teddy Graham buried $\sim 1 \mathrm{~cm}$ in the cage bedding and mouse replaced. The latency to find to the food was recorded (maximum session length $15 \mathrm{~min}$ ). The effect of genotype on latency was analyzed using ANOVA.

\section{Nesting Behavior}

Deficits in nest building are hypothesized to relate to selfneglect in schizophrenia (Koh et al, 2008; Lijam et al, 1997; Miyakawa et al, 2003). To examine nesting behaviors in GLAST KO, mice were single housed in a clean cage (9-10 females per genotype, 7-10 males per genotype) and provided with a standard cotton nestlet square (Ancare, Bellmore, NY). The following day, nesting material was removed and the mouse was provided with a new nestlet square. Four hours later, the quality of nest was scored on a five-point rating scale based upon (Deacon, 2006), as follows: $1=$ nestlet not noticeably touched, $2=$ nestlet partially torn up, $3=$ mostly shredded but no identifiable nest site, $4=$ an identifiable, but flat nest, $5=$ a well-defined nest with walls $>$ mouse body height. Because these data did not meet assumptions for a parametric statistical analysis, genotype effects on nesting score were analyzed using nonparametric Kruskal-Wallis ANOVA.

\section{Sucrose Preference}

Anhedonia was measured by preference for a sucrose solution over water, using a two-bottle free choice method as previously described (Bechtholt et al, 2008; Krishnan et al, 2007). Individually housed mice were first habituated to accessing tap water through $2 \times 50-\mathrm{ml}$ Falcon tubes fitted with sipper tubes for 4 days (Ancare). Every 4 days thereafter, one of the two water bottles was replaced with a bottle containing increasing sucrose concentrations $(1,2$, $4,8,16 \%)$. After this escalation procedure, mice were offered water $v s$ decreasing sucrose concentrations $(16,8$, $4 \%$, each for 4 days) and consumption was measured daily (correcting for evaporation/spillage using a 'dummy cage') and used to calculate average sucrose preference (sucrose intake/total intake) for each concentration. Every 2 days, solutions refreshed and left/right position of the bottles switched to control for any side bias.

\section{Acoustic Startle and Sensorimotor Gating}

For assessment of sensorimotor gating, acoustic startle, and prepulse inhibition (PPI) of the startle response was measured (Millstein et al, 2006; procedure same as previously described in our laboratory: see Supplementary Material and Methods for details).

\section{Auditory Brainstem Responses}

Auditory brainstem responses (ABRs) were obtained from mice anesthetized with a mixture of nitrous oxide/oxygen $(1: 1)$ gas and $3 \%$ halothane. Responses were differentially recorded between subcutaneously stainless steel electrodes at the vertex (active) and mastoid (reference). The ABRs, in response to the click sound, were recorded using a signal processor (NEC Synax 1200; Tokyo, Japan). The average of 300 responses was measured. The threshold was defined as the intensity level at which an ABR wave I with an amplitude of $0.05 \mu \mathrm{V}$ was seen in 2 averaged runs.

\section{Instrumental Learning and Extinction, Pairwise Discrimination Learning and Reversal}

We next turned to measures of executive/cognitive function in GLAST KO mice. One cohort of mice was tested for instrumental learning and extinction was tested (Brigman et al, 2008; Hefner et al, 2008) and another for pairwise discrimination learning and reversal, both using a murine touchscreen-based operant system (procedures same as previously described in our laboratory: see Supplementary Material and Methods for details).

\section{Pairwise Discrimination Learning and Reversal}

Mice underwent pretraining as above and then received an additional phase in which responses at a blank window during stimulus presentation produced a $5 \mathrm{~s}$ time-out (signaled by extinction of the house light) to discourage indiscriminate screen responding. Incorrect responses were followed by correction trials in which the same stimulus and spatial configuration was presented until a correct response was made. Performance criterion on this phase was $\geqslant 90 \%$ correct responses (excluding correction trials) over a 30trial session. Pairwise discrimination learning was tested as previously described (Brigman et al, 2008; Bussey et al, 1997; Izquierdo et al, 2006). Two novel approximately equiluminescent stimuli were presented in spatially 
pseudorandomized manner over 30-trial sessions (15 s ITI). Responses at one stimulus (correct) resulted in reward; responses at the other stimulus (incorrect) resulted in a $5 \mathrm{~s}$ time-out (signaled by extinction of the house light) and were followed by a correction trial. Stimuli remained on screen until a response was made. Designation of the correct and incorrect stimulus was counterbalanced across genotype (and where appropriate, drug). Performance criterion was $85 \%$ correct (excluding correction trials) on each of 2 consecutive days. The session after attaining discrimination criterion, the designation of stimuli as correct $v s$ incorrect was reversed for each mouse and performance tested over 30-trial daily sessions to a criterion of $85 \%$ correct (excluding correction trials) on each of 2 consecutive days. A maximum score of 1800 trials was assigned to any mouse that failed to reach criterion in 60 sessions.

The effect of genotype on total trials and incorrect responses committed to attain discrimination and reversal criteria, as well as omissions, average stimulus reaction time, average reward retrieval latency, and average session completion time, were checked for homogeneity of variance and analyzed using ANOVA followed by Newman-Keuls post hoc analysis and nonparametric Kruskal-Wallis ANOVA where appropriate. Because this analysis revealed a major effect of genotype on discrimination learning, two additional analyses were performed to further dissect the nature of the genotypic difference. A survival analysis was conducted using the Mantel-Cox test to quantify the percentage of mice within each genotype performing the task after a given number of sessions (up to a maximum of 60 sessions). The percentage of each genotype achieving thresholds of discrimination performance-ie, achieving two or more consecutive sessions at either 60, 65, $70,75,80$, or $85 \%$ correct responding was also measured, with $>70 \%$ correct considered significantly greater than chance (ie, $>2$ standard deviations above $50 \%$ in a 30 -trial session).

\section{Effects of mGlu2/3 Agonist LY379268 on Discrimination Learning}

As noted in Introduction section, we have previously demonstrated that GLAST KO exhibit locomotor hyperactivity in response to novelty that is normalized by treatment with the mGlu2/3 agonist LY379268 (Karlsson et al, 2008). As current data showed a significant deficit in discrimination learning in GLAST KO (see Results section), we next tested whether LY379268 treatment could normalize this performance deficit. A cohort of test-naive WT and KO (HET were not tested as they did not show a baseline abnormality) underwent pretraining as above with the exception that pretraining criteria were reduced from 90 to $75 \%$ (experiments in C57BL/6J showed that this expedited pretraining without affecting resultant discrimination performance (Brigman et al, unpublished). Thirty minutes before discrimination sessions, mice were injected intraperitoneally with either saline vehicle or $1.0 \mathrm{mg} / \mathrm{kg}$ LY379268 (Tocris, Ellisville, MI). This dose and route of administration normalizes the novelty-induced locomotor hyperactivity phenotype in GLAST KO (Karlsson et al, 2008). Testing and treatment continued until all WT mice had attained the $85 \%$ performance criterion.

\section{Statistical Analysis}

Data were analyzed using Statistica (Statsoft, Tulsa, OK, USA). For all analyses we included sex as a factor in all our models to determine whether sex was a significant influence.

\section{RESULTS}

\section{Functional Observation Battery}

There were no notable genotype differences on various measures of empty cage behavior, physical health, sensory, and neurological function (Table 1).

\section{Novelty-Induced Locomotor Activity}

There was a significant effect of genotype $\left(\mathrm{F}_{2,25}=8.36\right.$, $P=0.0017)$, and time $\left(F_{11,275}=15.00, P<0.0001\right)$ but no significant genotype $\times$ time interaction for total distance traveled (Figure 1a). Post hoc tests collapsed across the session showed that $\mathrm{KO}$ mice were significantly more active than WT (Figure 1b). There was no significant effect of genotype on percent time spent or frequency to enter the center of the open field for either the whole session or during the first $5 \mathrm{~min}$ when the anxiety response is considered to be the strongest (data not shown). When sex was added to the model, there was no significant effect of sex or genotype $\times$ sex interaction but there was a significant time $\times$ genotype $\times$ sex interaction $\left(\mathrm{F}_{22,242}=2.19\right.$, $P=0.0020)$ for total distance traveled. Post hoc analysis revealed a faster habituation to the open field in female GLAST HET mice compared to male KOs.

\section{Sociability and Social Novelty Preference}

There was a significant effect of genotype $\left(\mathrm{F}_{2,98}=6.62\right.$, $P=0.0020)$ and stimulus $\left(\mathrm{F}_{1,98}=53.21, P<0.0001\right)$, as well as a significant genotype $\times$ stimulus interaction $\left(\mathrm{F}_{2,98}=5.19, P=0.0072\right)$ for time spent sniffing during the sociability test. Post hoc tests showed WT and HET spent more time sniffing the cage containing the mouse than the empty cage. However, KO spent significantly less time sniffing the social stimulus than WT (Figure 2a). There was a significant effect of stimulus $\left(\mathrm{F}_{1,98}=12.41, P=0.0007\right)$ but no genotype or genotype $\times$ stimulus interaction for frequency to sniff during the sociability test (data not shown). When sex was included in the analysis, there was a significant sex $\times$ stimulus interaction on time $\left(\mathrm{F}_{1,92}=4.38\right.$, $P=0.039)$ and frequency $\left(\mathrm{F}_{1,92}=7.75, P=0.0065\right)$, because of male mice sniffing the inanimate, but not social, stimulus more than females there was no significant main effect or interactions between sex and genotype. For mean sniffing time there was no significant effect of genotype, but a significant effect of stimulus $\left(\mathrm{F}_{1,98}=32.68, P<0.0001\right)$ and genotype $\times$ stimulus interaction $\left(F_{2,98}=3.29, P=0.041\right)$. Post hoc analysis revealed that GLAST KO mice spent on average less time sniffing the social stimulus mouse (mean duration sniffing, inanimate stimulus: $\mathrm{WT}=1.36 \pm 0.39 \mathrm{~s}$, 
Table I Genotypes were Similar in a Functional Observation Battery Assessing Physical Health, Sensory Reflexes, Neurological Functions, and Empty Cage Behaviors

\begin{tabular}{|c|c|c|c|}
\hline & WT & HET & KO \\
\hline \multicolumn{4}{|l|}{ Physical health } \\
\hline Bald patches & 0 & 0 & 0 \\
\hline Body weight (g) & $23.8 \pm 0.8$ & $27.2 \pm 1.0$ & $24.6 \pm 1.5$ \\
\hline Exophthalmus & 0 & 0 & 0 \\
\hline Kinked tail & 0 & 0 & 0 \\
\hline Kyphosis & 0 & 0 & 0 \\
\hline Lordosis & 0 & 0 & 0 \\
\hline Missing whiskers & 18 & 0 & 0 \\
\hline Straub tail & 0 & 0 & 0 \\
\hline \multicolumn{4}{|l|}{ Empty cage behaviors } \\
\hline Abnormal gait & 0 & 0 & 0 \\
\hline Circling & 0 & 0 & 0 \\
\hline Defecation & 0 & 0 & 18 \\
\hline Freezing & 0 & 0 & 0 \\
\hline Head bobbing & 0 & 0 & 0 \\
\hline Jumping & 0 & 9 & 0 \\
\hline Licking & 0 & 0 & 0 \\
\hline Rearing & 100 & 100 & 100 \\
\hline Seizure & 0 & 0 & 0 \\
\hline Sniffing & 100 & 100 & 100 \\
\hline Trembling & 0 & 0 & 0 \\
\hline Retropulsion & 0 & 0 & 0 \\
\hline Urination & 0 & 0 & 0 \\
\hline Wild running & 0 & 9 & 9 \\
\hline \multicolumn{4}{|l|}{ Sensory reflexes } \\
\hline Approach responses & 100 & 100 & 100 \\
\hline Touch responses & 100 & 100 & 100 \\
\hline Palpebral responses & 100 & 100 & 100 \\
\hline Pinna reflex & 100 & 100 & 100 \\
\hline Tail pinch reflex & 100 & 100 & 100 \\
\hline Hot plate latency (s) & $10.6 \pm 0.6$ & $10.1 \pm 0.6$ & $9.5 \pm 0.7$ \\
\hline \multicolumn{4}{|l|}{ Motor, neurological } \\
\hline Forepaw clutch & 54.5 & 54.4 & 63.6 \\
\hline Hanging wire (s) & $52.8 \pm 4.4$ & $51.7 \pm 4.3$ & $55.5 \pm 4.5$ \\
\hline Hindpaw clutch & 0 & 0 & 0 \\
\hline Splayed limbs & 0 & 0 & 0 \\
\hline
\end{tabular}

Data denote the percentage of animals showing a response unless specified otherwise in parenthesis. $n=10-19$ per genotype.

$\mathrm{HET}=1.47 \pm 0.08, \quad \mathrm{KO}=1.44 \pm 0.12, \quad$ social $\quad$ stimulus: $\mathrm{WT}=2.82 \pm 0.39, \quad \mathrm{HET}=2.39 \pm 0.17, \quad \mathrm{KO}=1.87 \pm 0.15)$. There were no significant difference in transitions between the two stimuli $(\mathrm{WT}=20.25 \pm 1.78, \mathrm{HET}=21.47 \pm 1.22$, $\mathrm{KO}=19.59 \pm 1.49)$. There was no significant effect of genotype on latency to start sniffing either the empty or social stimulus cage (data now shown). Sex had no
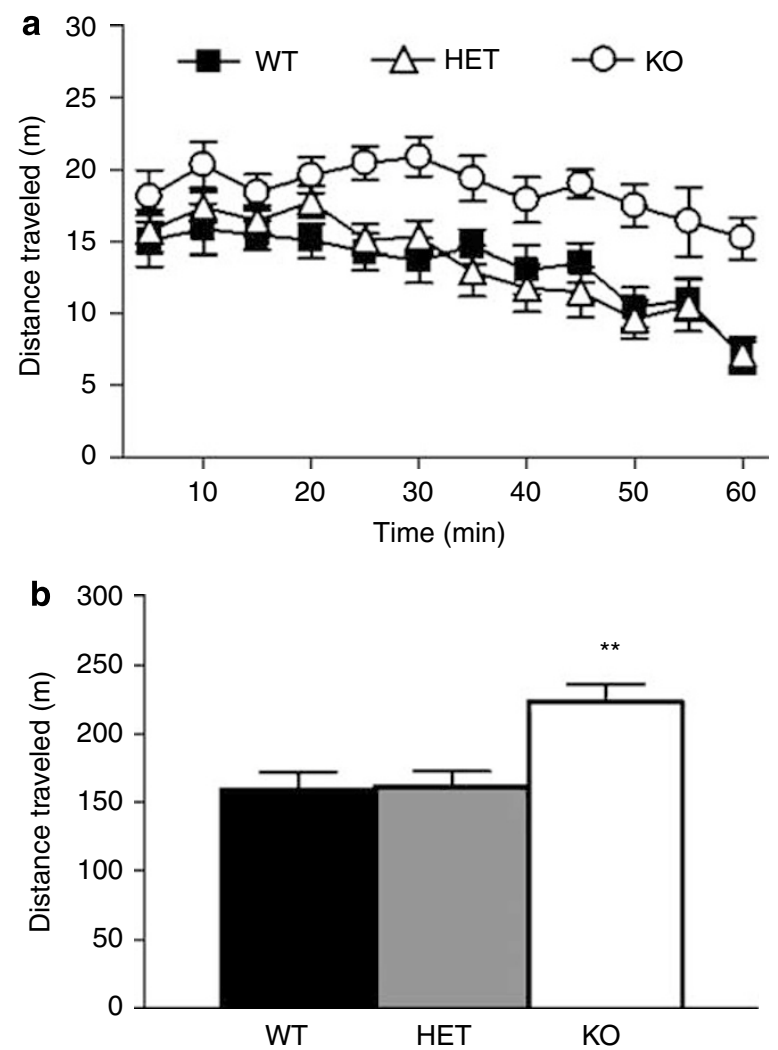

Figure I GLAST KO showed locomotor hyperactivity in a novel open field. GLAST KO mice show increased locomotor activity compared to WT controls (a). Over the session as a whole, GLAST KO were more active than WT (b). $n=10-19$ per genotype. Data are mean \pm SEM.

significant main effect or interaction on any of the parameters when incorporated into the analysis.

For the social novelty preference test, there was a significant effect of genotype $\left(F_{2,98}=4.46, P=0.014\right)$ and stimulus $\left(\mathrm{F}_{1,98}=72.86, P=0.0000\right)$ and a significant genotype $\times$ stimulus interaction $\left(\mathrm{F}_{2,98}=3.19, P=0.045\right)$ for time spent sniffing. Post hoc analysis showed that all genotypes spent more time sniffing the cage containing the novel mouse than the familiar mouse. However, KO spent significantly less time sniffing both the novel and the familiar mouse compared to WT (Figure 2b). There was a significant effect of stimulus $\left(\mathrm{F}_{1,98}=56.98, P<0.0001\right)$ but no genotype or genotype $\times$ stimulus interaction for frequency to sniff during social novelty preference test (data not shown). For average time sniffing there was a significant effect of genotype $\left(\mathrm{F}_{2,98}=11.10, P<0.0001\right)$, stimulus $\left(\mathrm{F}_{1,98}=16.58, P=0.0001\right)$, and genotype $\times$ stimulus interaction $\left(\mathrm{F}_{2,98}=4.17, P=0.011\right)$. Post hoc test showed GLAST KO spent significantly less time sniffing the familiar mouse and both GLAST HET and KO mice spent less time sniffing the novel stimulus mouse compared to WT controls (mean duration sniffing, familiar stimulus: $\mathrm{WT}=1.82 \pm 0.10 \mathrm{~s}$, $\mathrm{HET}=2.08 \pm 0.20, \quad \mathrm{KO}=1.37 \pm 0.17, \quad$ novel stimulus: $\mathrm{WT}=2.83 \pm 0.14, \quad \mathrm{HET}=2.13 \pm 0.16, \quad \mathrm{KO}=1.86 \pm 0.13)$ There was no significant difference in transitions between the familiar and novel stimuli (WT=14.69 \pm 2.84 , $\mathrm{HET}=11.35 \pm 1.18, \mathrm{KO}=10.24 \pm 1.25)$. No significant differences between genotype on latency to start sniffing either the familiar or novel stimulus cage were seen (data now 

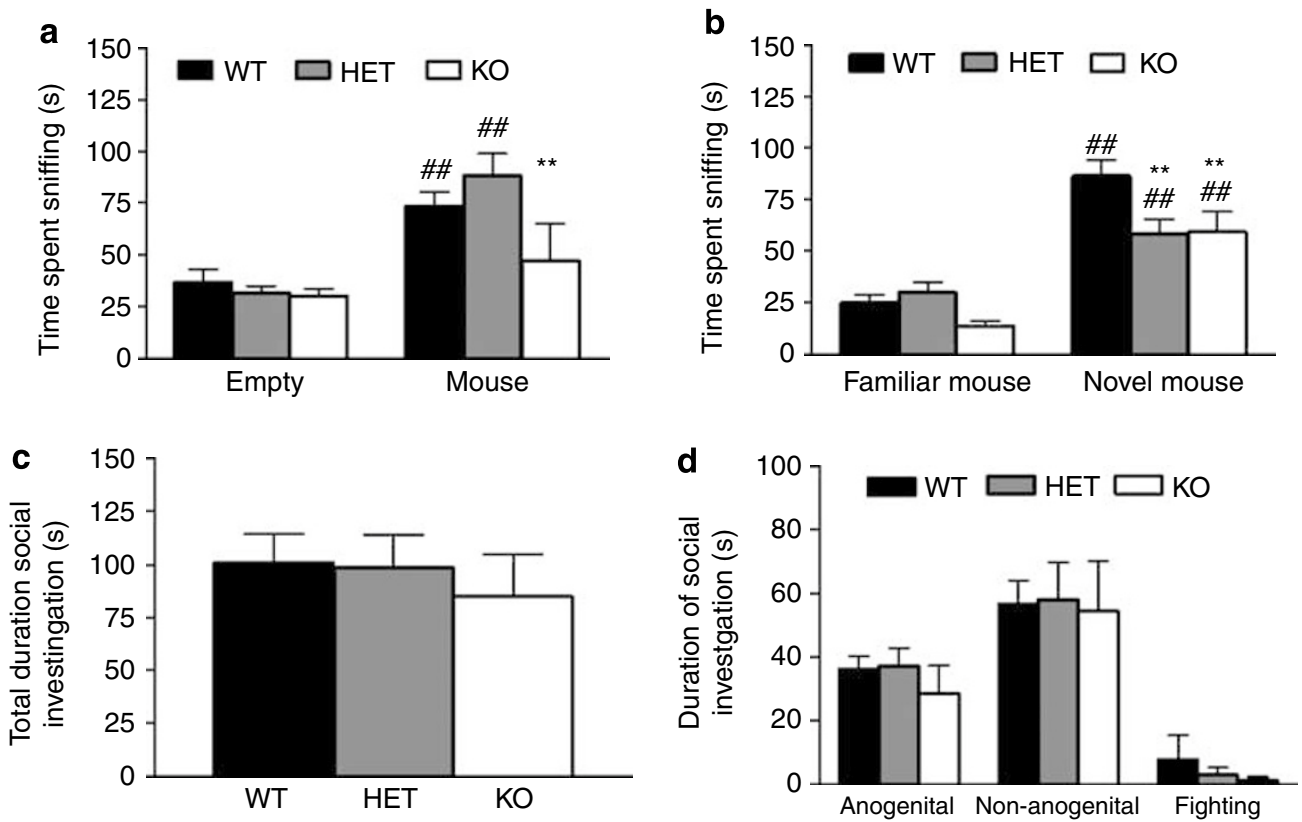

Figure 2 Decreased sociability and social novelty preference, but normal free social interaction in GLAST KO mice. WT and HET, but not KO, spent more time sniffing a cage containing a mouse than an empty cage, and $\mathrm{KO}$ spent less time sniffing the mouse-containing cage than WT controls (a). All genotypes spent more time sniffing a cage containing a novel mouse than a familiar mouse, but $\mathrm{KO}$ spent less time sniffing either stimulus than WT, whereas HET spent less time sniffing the novel stimulus than WT (b). Total time spent investigating an unfamiliar stimulus mouse in a free dyadic encounter did not differ between genotypes (c). Time spent engaged in anogenital and nonanogenital investigation, or aggression, did not differ between genotypes (d). $n=17-22$ per genotype. ${ }^{*} * P<0.0$ I vs $W T ;{ }^{\#} P<0.0$ I vs empty cage or familiar mouse-containing cage for same genotype. Data are mean \pm SEM.

Table 2 Poor Nesting Behavior in GLAST KO

\begin{tabular}{cccc}
\hline & WT & HET & KO \\
\hline Nesting score & $3.17 \pm 0.35$ & $3.47 \pm 0.34$ & $2.29 \pm 0.36$
\end{tabular}

GLAST had poorer nesting scores than WT as measured on a five-point rating scale.

$n=17-19, * P<0.05$. Data are mean \pm SEM.

shown). Sex had no significant main effect or interaction on any of the parameters when incorporated into the analysis.

\section{Free Social Interaction}

There was no significant effect of genotype on overall social interaction (Figure 2c) or duration of anogenital, nonanogenital or aggressive interactions (Figure $2 \mathrm{~d}$ ). There was a significant main effect of sex, (but no interactions with genotype), on overall social interaction $\left(F_{1,53}=7.74\right.$, $P=0.0075)$ as well as nonanogenital interaction $\left(\mathrm{F}_{1,53}=8.54, P=0.0051\right)$ because of males engaging in more interaction than females.

\section{Hidden Food Retrieval Test for Olfaction}

One WT and one KO failed to find the cookie within the time limit and were excluded. There was no effect of genotype on the latency to find the buried food $(\mathrm{WT}=189 \pm 52 \mathrm{~s}, \mathrm{HET}=113 \pm 23, \mathrm{KO}=153 \pm 43)$. There was a significant main effect of $\operatorname{sex}\left(\mathrm{F}_{1,49}=4.39, P=0.041\right.$; $n=16-20)$, but no interaction with genotype, because of a longer latency to find the cookie in males than females.

\section{Nesting Behavior}

There was a significant difference between genotypes in nesting behavior scores $\left(H_{2,53}=6.05, P=0.048\right)$. Post hoc analysis showed that KO made poorer nests than both WT and HET mice (Table 2). There was no main effect or interaction of sex with genotype on this measure.

\section{Sucrose Preference}

There was no effect of genotype or sucrose concentration, or an interaction between the two, for sucrose preference (Table 3). Total fluid intake was also unaffected by genotype and sucrose concentration. When sex was added to the statistical model, there was no main effect of sex or genotype $\times$ sex interaction for preference, although there was a significant effect of sex $\left(\mathrm{F}_{1,36}=10.79, P=0.0041\right)$ and a significant sex $\times$ sucrose concentration interaction $\left(\mathrm{F}_{2,36}=6.64, P=0.0035\right)$ for total intake because of females consuming more total fluid than males.

\section{Acoustic Startle and Sensorimotor Gating}

There was a significant effect of prepulse intensity $\left(\mathrm{F}_{2,104}=81.27, P<0.0001\right)$ but not of genotype and no prepulse intensity $\times$ genotype interaction for percent PPI. Post hoc tests collapsed across genotype showed a progressive increase in percent PPI with increasing prepulse intensities (Figure 3a). 
Table 3 GLAST KO Mice Showed Normal Preference for Sucrose

\begin{tabular}{lccc}
\hline & \multicolumn{3}{c}{ Sucrose concentration (\%) } \\
\cline { 2 - 4 } & $\mathbf{1 6}$ & $\mathbf{8}$ & $\mathbf{4}$ \\
\hline WT & $0.96 \pm 0.02$ & $0.98 \pm 0.01$ & $0.98 \pm 0.01$ \\
HET & $0.95 \pm 0.03$ & $0.95 \pm 0.03$ & $0.98 \pm 0.01$ \\
KO & $0.95 \pm 0.03$ & $0.99 \pm 0.01$ & $0.97 \pm 0.01$ \\
\hline
\end{tabular}

$n=8$ per genotype. Data are mean \pm SEM, preference ratio (= sucrosecontaining fluid intake/total fluid intake).
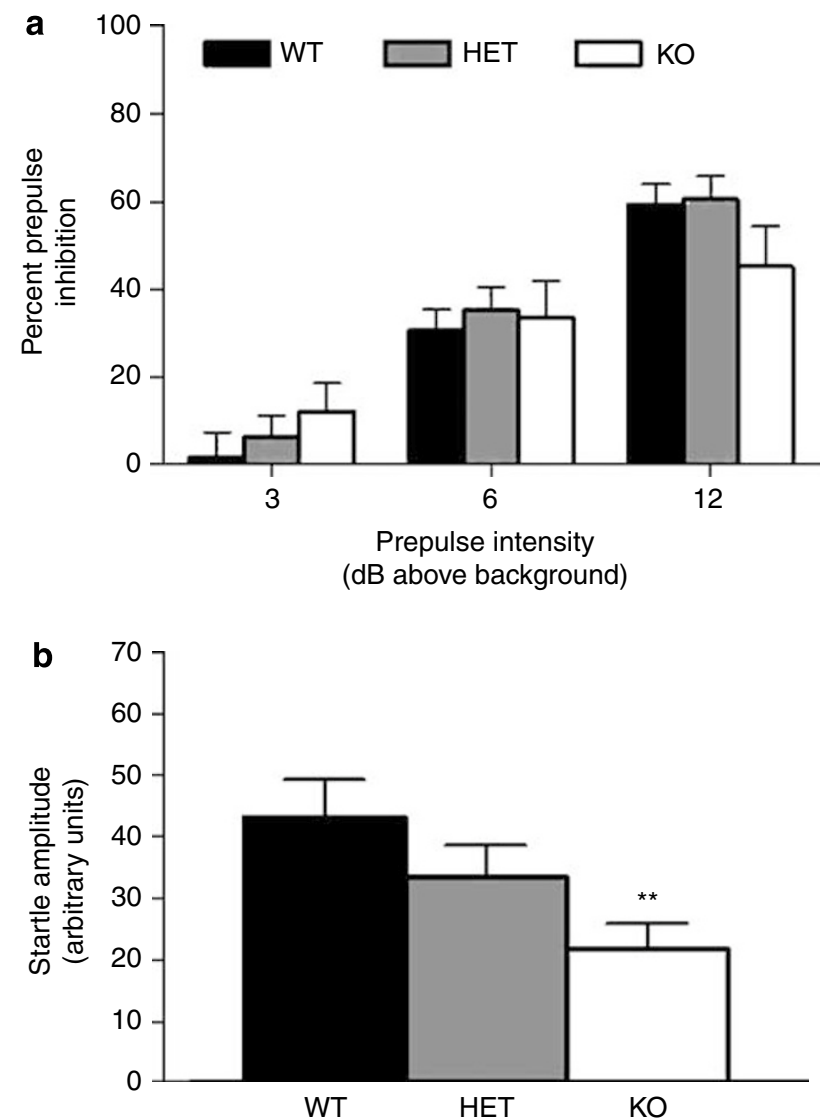

Figure 3 GLAST KO showed a reduced acoustic startle response but normal sensorimotor gating. Prepulse inhibition of the startle response was no different between genotypes regardless of prepulse intensity (a). GLAST $\mathrm{KO}$ showed a lesser acoustic startle response than WT (b). $n=13-22$ per genotype. $* * * 0.0$ I vs WT. Data are mean \pm SEM.

There was a significant effect of genotype for acoustic startle amplitude $\left(\mathrm{F}_{2,52}=5.47, P=0.0070\right)$. Post hoc tests revealed significantly lower startle amplitude in KO than WT (Figure 3b). Baseline movement did not differ between genotypes (data not shown). Sex had no significant main effect or interactions with genotype on either PPI or startle.

\section{Auditory Brainstem Responses}

There is no significant difference in the ABR thresholds between KO $(28.3 \pm 4.0 \mathrm{~dB}$ SPL, $n=6)$ and WT $(29.2 \pm 2.0 \mathrm{~dB}$ SPL, $n=6)$.
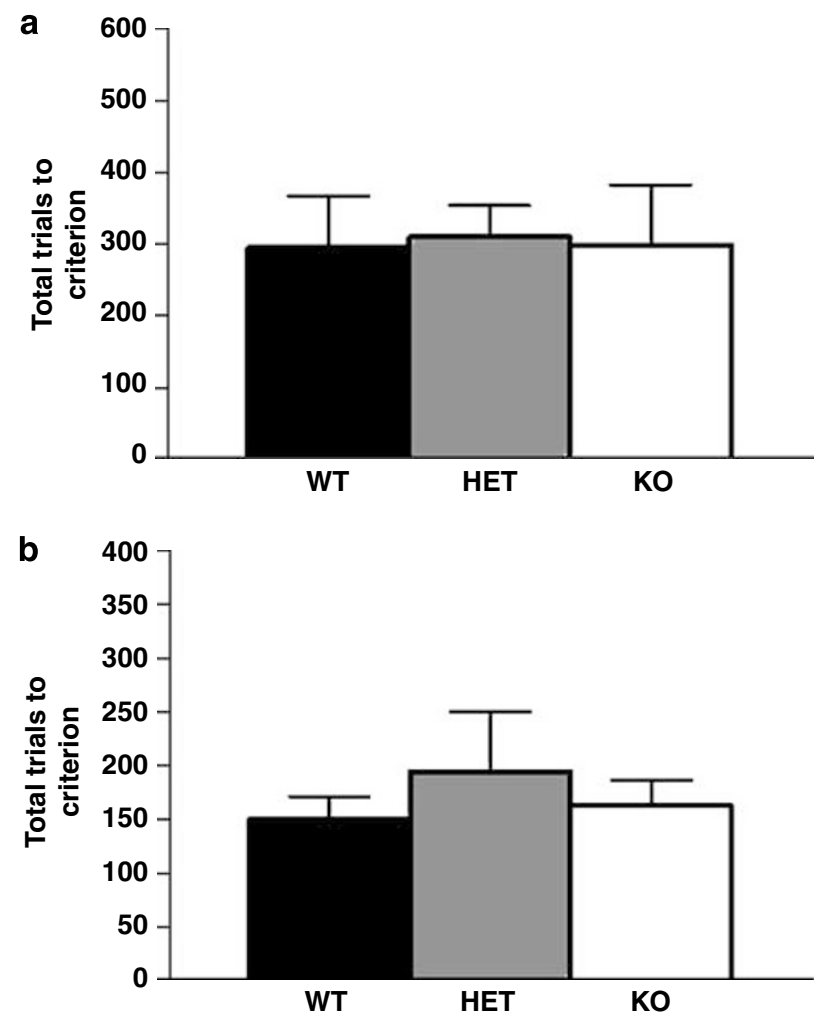

Figure 4 GLAST $K O$ showed normal instrumental learning and extinction. Genotypes did not differ in trials to instrumental learning criterion (a). Genotypes did not differ in trials to instrumental extinction criterion (b). $n=7-9$ per genotype. Data are mean \pm SEM.

Table 4 Genotypes did not Differ in Rate to Progress Through Pretraining Phases

\begin{tabular}{llll}
\hline & WT & HET & KO \\
\hline Pretraining phase 1 & $1.1 \pm 0.1$ & $1.4 \pm 0.3$ & $1.6 \pm 0.3$ \\
Pretraining phase 2 & $9.1 \pm 6.0$ & $9.1 \pm 4.4$ & $3.0 \pm 0.5$ \\
Pretraining phase 3 & $3.3 \pm 1.2$ & $2.7 \pm 0.9$ & $3.3 \pm 1.3$ \\
Pretraining phase 4 & $6.0 \pm 2.4$ & $5.1 \pm 2.0$ & $7.6 \pm 1.6$ \\
\hline
\end{tabular}

$n=7-9$ per genotype. Data are mean \pm SEM number of sessions to attain criterion.

\section{Instrumental Learning and Extinction}

Genotypes did not differ in trials to instrumental learning criteria (Figure 4a) or trials to extinction criterion (Figure $4 \mathrm{~b}$ ). There was no significant effect of sex and no genotype $\times$ sex interaction for these measures.

\section{Pairwise Discrimination Learning and Reversal}

Genotypes did not differ in sessions to criterion on any phase of pretraining (Table 4). For discrimination learning, there was a significant effect of genotype for total trials $\left(\mathrm{F}_{2,21}=56.8, \quad P<0.0001\right)$ and incorrect responses $\left(\mathrm{F}_{2,21}=72.14, P<0.0001\right)$ committed. Post hoc tests showed that KO committed significantly more trials (Figure 5a) and 

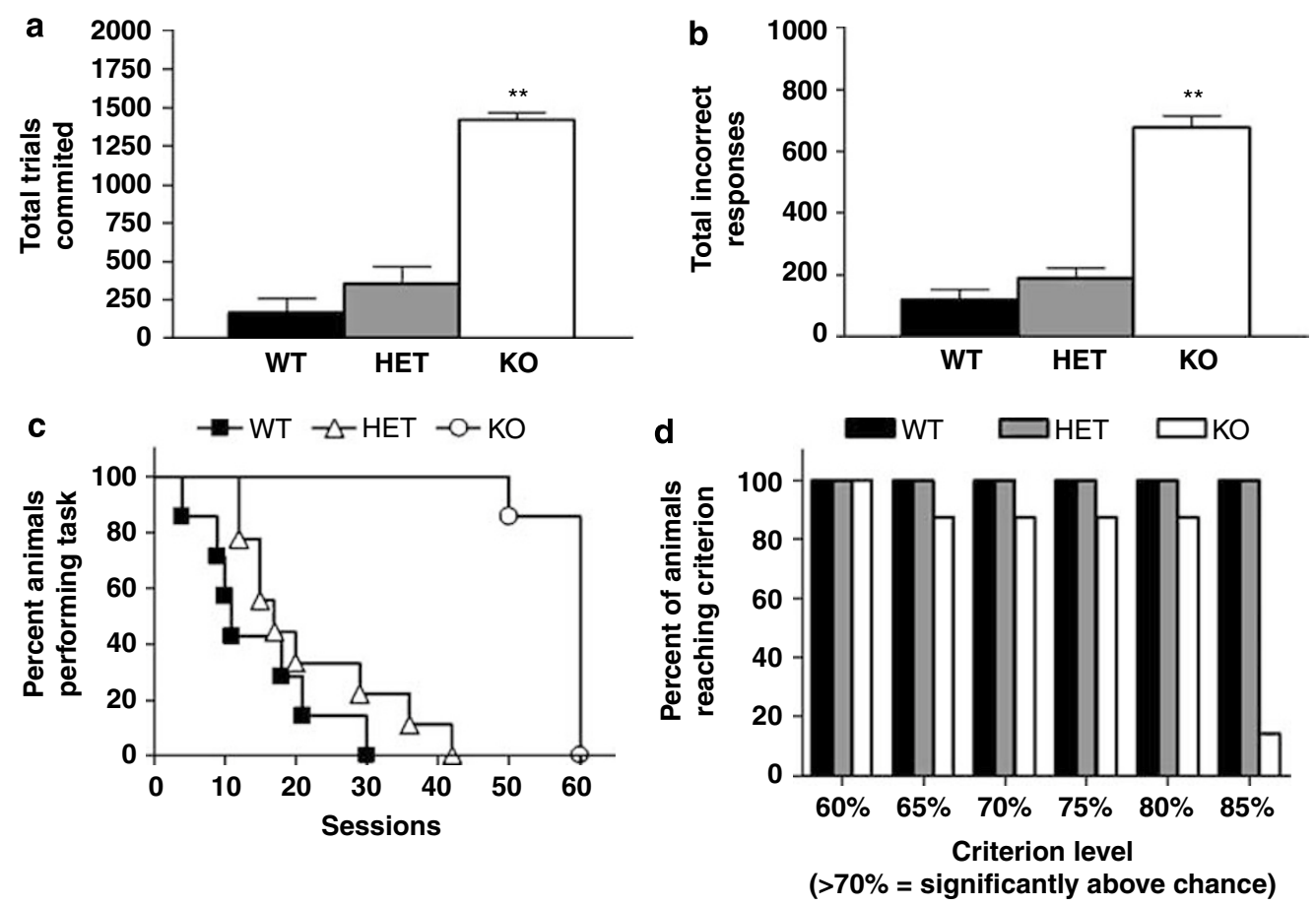

Figure 5 GLAST KO showed impaired pairwise discrimination learning. GLAST KO committed (a) more trials and (b) incorrect responses than WT over a maximum of 60 discrimination sessions. (c) Survival analysis showed that all WT and HET had attained the 85\% correct criterion by 30-40 sessions whereas only one $\mathrm{KO}$ had attained criterion after 60 sessions. (d) Analysis of the percentage of each genotype attaining increasing performance thresholds revealed that nearly $\mathrm{KO}$ were able to attain a $80 \%$ correct criterion level that was well above statistical chance (ie, $>70 \%$ correct). $n=7-9$ per genotype. $* * P<0.01$ vs WT. Data are mean \pm SEM.

Table 5 Auxiliary Measures of Task Performance During Discrimination Learning in GLAST KO Mice

\begin{tabular}{lrrr}
\hline & \multicolumn{1}{c}{ WT } & \multicolumn{1}{c}{ HET } & \multicolumn{1}{c}{ KO } \\
\hline Reaction time (s) & $14.3 \pm 4.0$ & $12.1 \pm 3.5$ & $5.8 \pm 1.2$ \\
Pellet retrieval latency (s) & $4.7 \pm 1.8$ & $3.0 \pm 1.1$ & $1.3 \pm 1.1$ \\
Session completion time (min) & $30.6 \pm 5.1$ & $26.6 \pm 3.5$ & $21.4 \pm 2.1$ \\
\hline
\end{tabular}

Data are mean \pm SEM. $n=7-9$ per genotype.

made significantly more incorrect responses (Figure $5 b$ ) over the course of the discrimination problem than WT. There was no significant effect of genotype for trials omitted or in any of the auxiliary measures (Table 5), although $\mathrm{KO}$ mice tended to omit less $(\mathrm{WT}=41.1 \pm 24.6$, $\mathrm{HET}=21.3 \pm 9.4, \mathrm{KO}=8.4 \pm 2.5)$ and respond to stimuli, retrieve rewards and complete sessions more quickly than WT. There was no significant effect of sex and no genotype $\times$ sex interaction for these measures.

Survival analysis revealed a significant effect of genotype $\left(\chi^{2}=14.51, \mathrm{df}=1, P<0.0001\right)$ WT and HET had attained the $85 \%$ correct criterion by $30-40$ sessions, whereas nearly all KO had failed to reach this criterion after the 60 -session cutoff (Figure 5c). However, analysis of the percentage of each genotype attaining increasing performance thresholds revealed that nearly all $\mathrm{KO}$ were able to attain a $80 \%$ correct criterion level that was well above statistical chance (ie, $>70 \%$ correct; Figure 5d).

Because KO failed to attain the preset $85 \%$ criterion for discrimination learning, they were not tested for reversal. WT and HET did not differ in the number of trials committed $(\mathrm{WT}=583 \pm 205, \mathrm{HET}=604 \pm 127)$ or incorrect responses $(\mathrm{WT}=336 \pm 81$, HET $=348 \pm 56$ ) to attain reversal criterion. Trials omitted, stimulus reaction time, reward retrieval latency, and session completion time were also no different between WT and HET (data not shown). Sex had no significant main effect or interaction with genotype on these analyses.

\section{Effects of LY379268 on Discrimination}

All WT attained the $85 \%$ correct discrimination criterion within 22 sessions. There was a significant effect of genotype but not treatment and no genotype $\times$ treatment interaction for trials committed $\left(\mathrm{F}_{1,25}=29.3, P=0.0003\right)$ and incorrect responses $\left(\mathrm{F}_{1,25}=67.3, P<0.0001\right)$ committed during these sessions. Post hoc analysis on data collapsed across treatment showed that $\mathrm{KO}$ committed significantly more trials (Figure 6a) and incorrect responses (Figure 6b) than WT. Survival analysis showed that all but one KO had failed to reach criterion over the 22 sessions, whether vehicle $\left(\chi^{2}=8.63, \mathrm{df}=1, \quad P<0.0001\right)$ or drug treated $\left(\chi^{2}=8.92, \mathrm{df}=1, P<0.0001\right.$; data not shown). For the 22 sessions when all mice were tested, $67 \%$ of the saline treated KO mice attained the $70 \%$ correct performance level (ie, significantly above chance) and drug treatment did not improve this rate (57\%). Sex produced no significant main effect or interaction with genotype or drug when incorporated into the analysis.

Because previous studies have shown that tolerance develops to LY379268's effects on motor coordination and nicotine self-administration (Cartmell et al, 2000; Liechti et al, 2007), although not the drug's effects on PCP-induced 

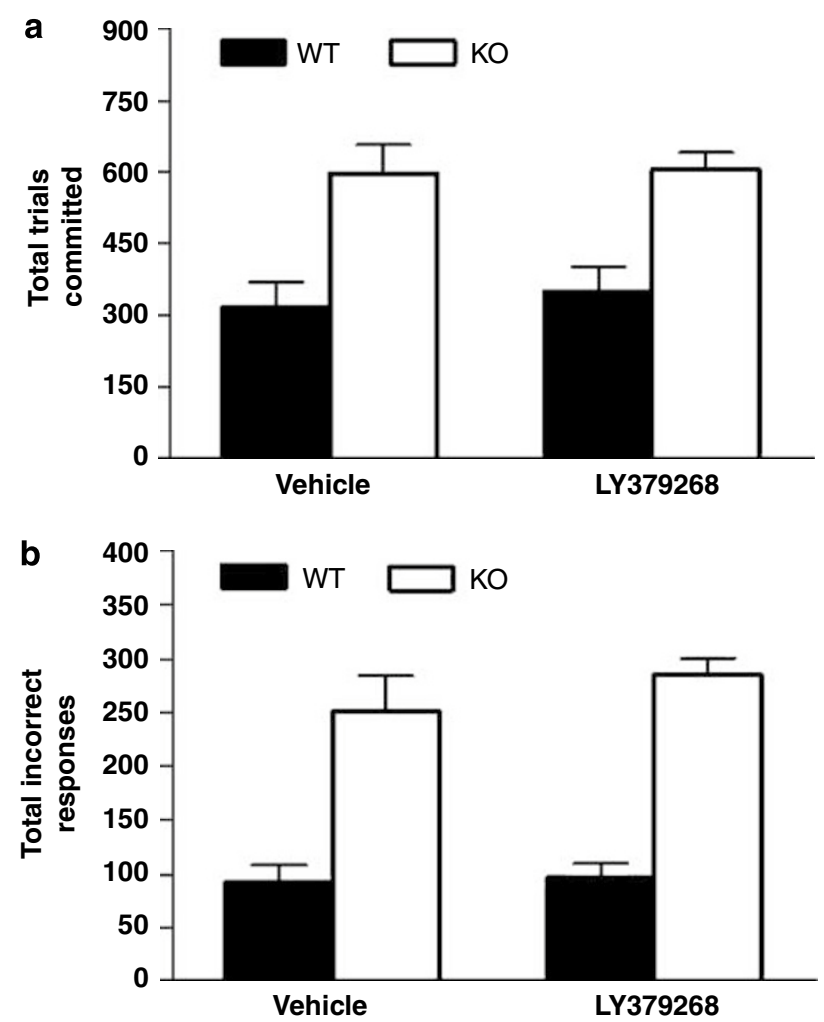

Figure 6 Treatment with the mGlu2/3 receptor agonist LY379268 did not rescue impaired pairwise discrimination learning in GLAST KO. Regardless of drug treatment, GLAST KO committed (a) more trials and (b) incorrect responses than WT over the 22 discrimination sessions taken for all WT mice to attain criterion. $n=6-8$ per genotype per treatment. Data are mean \pm SEM.

hyperactivity (Cartmell et al, 2000), we separately analyzed the first six sessions of discrimination for significant drug effects that might have waned with the more prolonged treatment. There was no indication that LY379268 produced effects on behavior early in training that were lost with repeated treatment, regardless of genotype (data not shown).

\section{DISCUSSION}

The main finding of this study was that GLAST-deficient mice exhibited abnormalities on certain behavioral measures considered relevant to the negative and attentional/ cognitive symptoms of schizophrenia.

GLAST KO but not HET exhibited a significant increase in total distance traveled during exposure to a novel open field. This replication confirms the robustness of the recent finding of novelty-induced locomotor hyperactivity in GLAST KO mice (Karlsson et al, 2008). Our earlier study found that these mutants were also hypersensitive to the locomotor hyperactivity-inducing effects of the NMDAR antagonist MK-801, and that novelty-induced hyperactivity normalized by the antipsychotic haloperidol and the mGlu2/3 agonist LY379268 (Karlsson et al, 2008). These phenotypes are posited to be related to the positive symptoms of schizophrenia (Arguello and Gogos, 2006; Powell and Miyakawa, 2006).

Current data showed that the phenotype of GLASTdeficient mice extends to behavioral abnormalities associated with negative symptomatology in schizophrenia. In this context, GLAST KO showed poor nesting behavior relative to their WT littermates. Deficits in nest building have been reported in other mouse mutants exhibiting 'schizophrenia-related' abnormalities on other measures (eg, calcineurin $\mathrm{KO}$, disheveled homolog $1 \mathrm{KO}$, phospholipase $\mathrm{C}-\beta 1 \mathrm{KO}$ ), and has been interpreted as a model of selfneglect in schizophrenia (Koh et al, 2008; Lijam et al, 1997; Miyakawa et al, 2003). Another major negative component of schizophrenia is social withdrawal. On an assay for sociability, GLAST KO did not show a preference for a social stimulus over an inanimate stimulus, in contrast to the significant social preference exhibited by WT and HET (and most inbred mouse strains; Crawley, 2007). Furthermore, whereas all genotypes including $\mathrm{KO}$ exhibited a preference for investigating a novel mouse over a familiar one, KO showed a lesser preference than WT. GLAST HET also displayed a deficit in this measure of social novelty preference. Interestingly, this was the only instance where the HET demonstrated a significant phenotypic abnormality in this study, indicating that GLAST haploinsufficiency is only sufficient to cause changes in select measures of 'schizophrenia-related behavior' we examined herein.

The precise nature of the social deficit in GLAST-deficient mice remains to be ascertained. Social withdrawal has been discussed in terms of a more general loss of interest in pleasurable activity (anhedonia; Arguello and Gogos, 2006), and anhedonia has been reported in some putative rodent models of schizophrenia (Hikida et al, 2007; Le Pen et al, 2002). In this context, we did not see alterations in anhedonia in GLAST KO as measured by a sucrose preference test. However, because preference levels were so high at the concentrations used, it remains possible that the hedonic properties of these concentrations were too high to detect a genotype difference. It is also worth noting that genotypes did not differ on a simple test for (nonsocial) olfaction, ruling out the possibility that generalized anosmia confounded social recognition. Furthermore, analysis of free social interaction in a dyadic encounter with a conspecific male did not reveal any obvious social deficits in GLAST KO. The reason why social behavior was normal under these testing conditions but not the social choice assays could be because of fact that in the free social interaction test, social encounters can be initiated by both mice, whereas in the choice tests the subject itself must initiate social encounters. Thus, one explanation for the pattern of the social phenotype observed is that GLAST mutant mice have a deficit in instigating social interaction, although GLAST KO showed no markedly gross abnormalities on a battery of simple measures of physical health, sensory, and neurological function, KO mice did, however, show relatively fewer missing whiskers and more empty cage wild running/defecation possibly further indicating abnormal social and anxiety-related behavior, respectively.

Prepulse inhibition (PPI) of the startle response is a measure for sensorimotor gating that is impaired in schizophrenics and commonly used to evaluate rodent models of schizophrenia and the potential efficacy of antipsychotic medications (Geyer et al, 2002). GLAST KO showed a nonsignificant trend for impaired PPI, as well as a 
significant reduction in acoustic startle amplitude. PPI and startle are mediated by different neural systems and are dissociable at the behavioral level (Geyer et al, 2002). However, Hakuba et al (2000) have shown that GLAST KO develop hearing loss following exposure to loud noise and although mice in our study were not subjected to any such trauma (and showed normal auditory brainstem responses) it is possible that their reduced startle responses stemmed from a deficit in hearing and therefore remains possible that a hearing-related impairment of startle confounded detection of PPI deficits in GLAST KO.

There is growing emphasis on better defining and treating cognitive dysfunction in schizophrenia. The cognitive phenotype of schizophrenia and animal models of the disease has typically focused upon the executive component, as measured for example by attentional set-shifting and working memory. However, schizophrenic patients also present with impairments in various forms of memory and perception (for recent reviews, see Butler et al, 2008; Carter et al, 2008; Ranganath et al, 2008). One objective of this study was to test GLAST KO for various forms of instrumental learning and a measure of executive-related function (reversal). GLAST KO showed impaired pairwise visual discrimination learning as evidenced by a failure of most of the KOs tested to attain an a priori criterion of $85 \%$ correct choices over 60 test sessions. Importantly, however, a more detailed analysis of the data showed that KO were able to attain performance levels that were just short of this criterion (ie, $80 \%$ correct) but still well above chance. Furthermore, $\mathrm{KO}$ were unimpaired in the acquisition or extinction of a simple instrumental task, discounting a nonspecific impairment in operant performance. However, the failure of $\mathrm{KO}$ to reach discrimination criterion meant these mice could not be tested for reversal and evaluation of executive functions on others assays remains an important question for future studies. Taken together, the current data demonstrate a selective, partial deficit in pairwise discrimination learning in GLAST KO. Further work will be needed to determine the extent to which this impairment is related to the perceptual or associative learning demands of the task. The potential contribution of poor vision is another factor to be addressed given evidence that GLAST KO on a C57BL/6 genetic background (as currently used) have a loss of retinal ganglion cells (Harada et al, 1998, 2007).

We previously found that treatment with the mGlu2/3 receptor agonist LY379268 prevented novelty-induced locomotor hyperactivity in GLAST KO (Karlsson et al, 2008). The locomotor hyperactivity-inducing effects of NMDAR antagonists have been linked to GABAergic disinhibition of glutamate release and neuronal hyperexcitability in PFC (Moghaddam and Adams, 1998; Lorrain et al, 2003; Jackson et al, 2004; Homayoun and Moghaddam, 2007; Kargieman et al, 2007). Along similar lines, loss of GLAST-mediated glutamate reuptake could lead to excessive extracellular glutamate and neuronal hyperexcitability in PFC in response to novelty-provocation (although in vivo voitametry or microdialysis is still needed to provide direct support for this). In this scheme, negatively modulated extracellular PFC glutamate levels by LY379268 provides a potential mechanism for the drug's ability to normalize locomotor hyperactivity induced by novelty in GLAST KO and by NMDAR antagonist treatments in non-mutant rodents (Conn and Pin, 1997; Moghaddam and Adams, 1998; Patil et al, 2007). Current data show that LY379268 failed to rescue impaired discrimination learning in GLAST KO. This indicates that the deficit is not simply an artifact of locomotor hyperactivity and that the mechanisms underlying the discrimination phenotype in these mice is likely distinct from those driving the locomotor phenotype. Indeed, although the neural circuits mediating our discrimination task remain to be identified, preliminary evidence points to a greater role for dorsal striatum than PFC (Brigman et al, unpublished). In this context, it will be interesting to test whether drugs acting at other mGlu receptors subtypes known to modulate striatal function and plasticity (eg, mGlu5; Gubellini et al, 2004) would be effective in rescuing the discrimination phenotype in GLAST KO.

A final issue with regards to the mechanisms driving the behavioral abnormalities in GLAST-deficient mice relates to the constitutive nature of the mutation. As with any mouse mutant in which a gene is constitutively deleted, there is the potential both for developmental compensation and secondary changes caused by the chronic absence of the gene (Holmes, 2008). In this context, GLAST has an interesting pattern of developmental expression in mouse brain; with high transient postnatal GLAST gene promoter activity in cortex and hippocampus but a slow ontogenic rise in the cerebellum (Regan et al, 2007). However, previous studies show no alteration in protein expression of the other glutamate transporter subtypes (GLT-1, EAAC1, and EAAT4) in the cortex or cerebellum of GLAST KO mice (Watase et al, 1998; Voutsinos-Porche et al, 2003). Furthermore, although the combined KO of GLAST and another astrocytic transporter, GLT-1, causes developmental abnormalities in cortical layering, GLAST KO per se does not have marked effects on layering or somatosensory cortex barrel field formation (Matsugami et al, 2006; Takasaki et al, 2008). Nonetheless, these data do not rule out the possibility that constitutive loss of GLAST could produce developmental anomalies that contribute to the behavioral abnormalities reported in this study. Possible effects of excitotoxicity resulting from loss of GLAST also should not be discounted (Choi, 1988) given evidence that GLAST KO have increased vulnerability to cerebellar neurotoxicity and chronic antisense knockdown of GLAST causes damage to rat striatal neurons (Rothstein et al, 1996; Watase et al, 1998). In fact, any neurodegenerative and neurodevelopmental abnormalities in GLAST KO could be highly salient to the 'schizophrenia-related' phenotype of these mice, given current theories about the etiology of the disease (Olney and Farber, 1995; Harrison, 1999; Perez-Neri et al, 2006).

In summary, the results of this study provide evidence that gene deletion of the astrocytic glutamate transporter GLAST produces abnormalities on certain behavioral measures considered relevant to the positive, negative, and attentional/cognitive symptoms of schizophrenia. GLAST KO showed novelty-induced locomotor hyperactivity, abnormal social behavior characterized by reduced initiation of social interactions, poor nesting, and impaired pairwise visual discrimination learning. These findings are particularly interesting given recent evidence linking gene mutation of human GLAST (SCL3A) to schizophrenia 
(Walsh et al, 2008). Although no single rodent model of schizophrenia can recapitulate the symptom complexity and diversity of schizophrenia, GLAST-deficient mice provide one useful tool for elucidating the contribution of glutamate dysfunction to the pathophysiology of this disease.

\section{ACKNOWLEDGEMENTS}

We thank Dr Jeffrey Rothstein at the John Hopkins University for providing mutant mice for breeding, Dr Judith Davis and Monique Melige for assistance with breeding, and Ben Palachick and Jessica Ihne for technical assistance. We are also thankful to Gene S Fisch for expert statistical advice. This work was supported by the National Institute on Alcohol Abuse and Alcoholism Intramural Research Program. TK was supported by The Novartis Foundation (Japan) for the promotion of Science, Takeda Science Foundation, The Tokyo Biochemical Research Foundation, Research Foundation for Opto-Science and Technology, and by grants-in-aids for Scientific Research on Priority Area (20022013 and 18053006) provided by the Ministry of Education, Culture, Sports, Science, and Technology of Japan.

\section{DISCLOSURE/CONFLICT OF INTEREST}

The authors declare no conflicts of interest.

\section{REFERENCES}

Adler CM, Malhotra AK, Elman I, Goldberg T, Egan M, Pickar D et al (1999). Comparison of ketamine-induced thought disorder in healthy volunteers and thought disorder in schizophrenia. Am J Psychiatry 156: 1646-1649.

American Psychiatric Association (APA) (2000). Diagnostic and Statistical Manual of Mental Disorders, 4th edn. (text rev.), American Psychiatric Press: Washington, DC.

Arguello PA, Gogos JA (2006). Modeling madness in mice: one piece at a time. Neuron 52: 179-196.

Bauer D, Gupta D, Harotunian V, Meador-Woodruff JH, McCullumsmith RE (2008). Abnormal expression of glutamate transporter and transporter interacting molecules in prefrontal cortex in elderly patients with schizophrenia. Schizophr Res 104: 108-120.

Bechtholt AJ, Smith K, Gaughan S, Lucki I (2008). Sucrose intake and fasting glucose levels in 5-HT(1A) and 5-HT(1B) receptor mutant mice. Physiol Behav 93: 659-665.

Boyce-Rustay JM, Holmes A (2006). Genetic inactivation of the NMDA receptor NR2A subunit has anxiolytic- and antidepressant-like effects in mice. Neuropsychopharmacology 31: 24052414.

Brigman JL, Feyder M, Saksida LM, Bussey TJ, Mishina M, Holmes A (2008). Impaired discrimination learning in mice lacking the NMDA receptor NR2A subunit. Learn Mem 15: 50-54.

Bussey TJ, Muir JL, Everitt BJ, Robbins TW (1997). Triple dissociation of anterior cingulate, posterior cingulate, and medial frontal cortices on visual discrimination tasks using a touchscreen testing procedure for the rat. Behav Neurosci 111: 920-936.

Butler PD, Silverstein SM, Dakin SC (2008). Visual perception and its impairment in schizophrenia. Biol Psychiatry 64: 40-47.

Carter CS, Barch DM, Buchanan RW, Bullmore E, Krystal JH, Cohen J et al (2008). Identifying cognitive mechanisms targeted for treatment development in schizophrenia: an overview of the first meeting of the Cognitive Neuroscience Treatment Research to Improve Cognition in Schizophrenia Initiative. Biol Psychiatry 64: 4-10.

Cartmell J, Monn JA, Schoepp DD (2000). Tolerance to the motor impairment, but not to the reversal of PCP-induced motor activities by oral administration of the $\mathrm{mGlu} 2 / 3$ receptor agonist, LY379268. Naunyn Schmiedebergs Arch Pharmacol 361: 39-46.

Choi DW (1988). Glutamate neurotoxicity and diseases of the nervous system. Neuron 1: 623-634.

Conn PJ, Pin JP (1997). Pharmacology and functions of metabotropic glutamate receptors. Annu Rev Pharmacol Toxicol 37: 205-237.

Coyle JT (2006). Glutamate and schizophrenia: beyond the dopamine hypothesis. Cell Mol Neurobiol 26: 365-384.

Crawley JN (2007). Mouse behavioral assays relevant to the symptoms of autism. Brain Pathol 17: 448-459.

Crawley JN, Paylor R (1997). A proposed test battery and constellations of specific behavioral paradigms to investigate the behavioral phenotypes of transgenic and knockout mice. Horm Behav 31: 197-211.

Deacon RM (2006). Assessing nest building in mice. Nat Protoc 1: 1117-1119.

Deng X, Shibata H, Takeuchi N, Rachi S, Sakai M, Nimomiya H et al (2007). Association study of polymorphisms in the glutamate transporter genes SLC1A1, SLC1A3, and SLC1A6 with schizophrenia. Am J Med Genet B Neurpsychiatr Genet 144B: 271-278.

Geyer MA, McIlwain KL, Paylor R (2002). Mouse genetic models for prepulse inhibition: an early review. Mol Psychiatry 7: 10391053.

Gubellini P, Pisani A, Centonze D, Bernardi G, Calabresi P (2004). Metabotropic glutamate receptors and striatal synaptic plasticity: implications for neurological diseases. Prog Neurobiol 74: 271-300.

Hakuba N, Koga K, Gyo K, Usami SI, Tanaka K (2000). Exacerbation of noise-induced hearing loss in mice lacking the glutamate transporter GLAST. J Neurosci 20: 8750-8753.

Harada T, Harada C, Nakamura K, Quah HM, Okumura A, Namekata $\mathrm{K}$ et al (2007). The potential role of glutamate transporters in the pathogenesis of normal tension glaucoma. $J$ Clin Invest 117: 1763-1770.

Harada T, Harada C, Watanabe M, Inoue Y, Sakagawa T, Nakayama $\mathrm{N}$ et al (1998). Functions of the two glutamate transporters GLAST and GLT-1 in the retina. Proc Natl Acad Sci USA 95: 4663-4666.

Harrison PJ (1999). The neuropathology of schizophrenia. A critical review of the data and their interpretation. Brain 122(Part 4): 593-624.

Harrison PJ, Weinberger DR (2005). Schizophrenia genes, gene expression, and neuropathology: on the matter of their convergence. Mol Psychiatry 10: 40-68; image 5.

Hefner K, Whittle N, Juhasz J, Norcross M, Karlsson RM, Saksida LM et al (2008). Impaired fear extinction learning and corticoamygdala circuit abnormalities in a common genetic mouse strain. J Neurosci 28: 8074-8085.

Hikida T, Jaaro-Peled H, Seshadri S, Oishi K, Hookway C, Kong S et al (2007). Dominant-negative DISC1 transgenic mice display schizophrenia-associated phenotypes detected by measures translatable to humans. Proc Natl Acad Sci USA 104: 14501-14506.

Holmes A (2008). Genetic variation in cortico-amygdala serotonin function and risk for stress-related disease. Neurosci Biobehav Rev 32: 1293-1314.

Homayoun H, Moghaddam B (2007). NMDA receptor hypofunction produces opposite effects on prefrontal cortex interneurons and pyramidal neurons. J Neurosci 27: 11496-11500.

Izquierdo A, Wiedholz LM, Millstein RA, Yang RJ, Bussey TJ, Saksida LM et al (2006). Genetic and dopaminergic modulation 
of reversal learning in a touchscreen-based operant procedure for mice. Behav Brain Res 171: 181-188.

Jackson ME, Homayoun H, Moghaddam B (2004). NMDA receptor hypofunction produces concomitant firing rate potentiation and burst activity reduction in the prefrontal cortex. Proc Natl Acad Sci USA 101: 8467-8472.

Kargieman L, Santana N, Mengod G, Celada P, Artigas F (2007). Antipsychotic drugs reverse the disruption in prefrontal cortex function produced by NMDA receptor blockade with phencyclidine. Proc Natl Acad Sci USA 104: 14843-14848.

Karlsson RM, Heilig M, Holmes A (2008). Loss of glial glutamate and aspartate transporter (excitatory amino acid transporter 1) causes locomotor hyperactivity and exaggerated responses to psychotomimetics: rescue by haloperidol and metabotropic glutamate 2/3 agonist. Biol Psychiatry 64: 810-814.

Koh HY, Kim D, Lee J, Lee S, Shin HS (2008). Deficits in social behavior and sensorimotor gating in mice lacking phospholipase Cbeta1. Genes Brain Behav 7: 120-128.

Krishnan V, Han MH, Graham DL, Berton O, Renthal W, Russo SJ et al (2007). Molecular adaptations underlying susceptibility and resistance to social defeat in brain reward regions. Cell 131: 391-404.

Krystal JH, Anand A, Moghaddam B (2002). Effects of NMDA receptor antagonists: implications for the pathophysiology of schizophrenia. Arch Gen Psychiatry 59: 663-664.

Krystal JH, Karper LP, Seibyl JP, Freeman GK, Delaney R, Bremner JD et al (1994). Subanesthetic effects of the noncompetitive NMDA antagonist, ketamine, in humans. Psychotomimetic, perceptual, cognitive, and neuroendocrine responses. Arch Gen Psychiatry 51: 199-214.

Le Pen G, Gaudet L, Mortas P, Mory R, Moreau JL (2002). Deficits in reward sensitivity in a neurodevelopmental rat model of schizophrenia. Psychopharmacology (Berl) 161: 434-441.

Lewis DA, Gonzalez-Burgos G (2006). Pathophysiologically based treatment interventions in schizophrenia. Nat Med 12: 1016-1022.

Liechti ME, Lhuillier L, Kaupmann K, Markou A (2007). Metabotropic glutamate $2 / 3$ receptors in the ventral tegmental area and the nucleus accumbens shell are involved in behaviors relating to nicotine dependence. J Neurosci 27: 9077-9085.

Lijam N, Paylor R, McDonald MP, Crawley JN, Deng CX, Herrup K et al (1997). Social interaction and sensorimotor gating abnormalities in mice lacking Dvl1. Cell 90: 895-905.

Lorrain DS, Baccei CS, Bristow LJ, Anderson JJ, Varney MA (2003). Effects of ketamine and $N$-methyl-D-aspartate on glutamate and dopamine release in the rat prefrontal cortex: modulation by a group II selective metabotropic glutamate receptor agonist LY379268. Neuroscience 117: 697-706.

Malhotra AK, Pinals DA, Adler CM, Elman I, Clifton A, Pickar D et al (1997). Ketamine-induced exacerbation of psychotic symptoms and cognitive impairment in neuroleptic-free schizophrenics. Neuropsychopharmacology 17: 141-150.

Matsugami TR, Tanemura K, Mieda M, Nakatomi R, Yamada K, Kondo $\mathrm{T}$ et al (2006). From the cover: indispensability of the glutamate transporters GLAST and GLT1 to brain development. Proc Natl Acad Sci USA 103: 12161-12166.

McCullumsmith RE, Meador-Woodruff JH (2002). Striatal excitatory amino acid transporter transcript expression in schizophrenia, bipolar disorder, and major depressive disorder. Neuropsychopharmacology 26: 368-375.

McFarlane HG, Kusek GK, Yang M, Phoenix JL, Bolivar VJ, Crawley JN (2008). Autism-like behavioral phenotypes in BTBR $\mathrm{T}+\mathrm{tf} / \mathrm{J}$ mice. Genes Brain Behav 7: 152-163.

Millstein RA, Holmes A (2007). Effects of repeated maternal separation on anxiety- and depression-related phenotypes in different mouse strains. Neurosci Biobehav Rev 31: 3-17.
Millstein RA, Ralph RJ, Yang RJ, Holmes A (2006). Effects of repeated maternal separation on prepulse inhibition of startle across inbred mouse strains. Genes Brain Behav 5: 346-354.

Miyakawa T, Leiter LM, Gerber DJ, Gainetdinov RR, Sotnikova TD, Zeng $\mathrm{H}$ et al (2003). Conditional calcineurin knockout mice exhibit multiple abnormal behaviors related to schizophrenia. Proc Natl Acad Sci USA 100: 8987-8992.

Moghaddam B, Adams BW (1998). Reversal of phencyclidine effects by a group II metabotropic glutamate receptor agonist in rats. Science 281: 1349-1352.

Newcomer JW, Farber NB, Jevtovic-Todorovic V, Selke G, Melson AK, Hershey T et al (1999). Ketamine-induced NMDA receptor hypofunction as a model of memory impairment and psychosis. Neuropsychopharmacology 20: 106-118.

Olney JW, Farber NB (1995). Glutamate receptor dysfunction and schizophrenia. Arch Gen Psychiatry 52: 998-1007.

Olney JW, Newcomer JW, Farber NB (1999). NMDA receptor hypofunction model of schizophrenia. J Psychiatr Res 33: 523-533.

Patil ST, Zhang L, Martenyi F, Lowe SL, Jackson KA, Andreev BV et al (2007). Activation of $\mathrm{mGlu} 2 / 3$ receptors as a new approach to treat schizophrenia: a randomized phase 2 clinical trial. Nat Med 13: 1102-1107.

Perez-Neri I, Ramirez-Bermudez J, Montes S, Rios C (2006). Possible mechanisms of neurodegeneration in schizophrenia. Neurochem Res 31: 1279-1294.

Powell CM, Miyakawa T (2006). Schizophrenia-relevant behavioral testing in rodent models: a uniquely human disorder? Biol Psychiatry 59: 1198-1207.

Ranganath C, Minzenberg MJ, Ragland JD (2008). The cognitive neuroscience of memory function and dysfunction in schizophrenia. Biol Psychiatry 64: 18-25.

Regan MR, Huang YH, Kim YS, Dykes-Hoberg MI, Jin L, Watkins AM et al (2007). Variations in promoter activity reveal a differential expression and physiology of glutamate transporters by glia in the developing and mature CNS. J Neurosci 27: 6607-6619.

Rothstein JD, Dykes-Hoberg M, Pardo CA, Bristol LA, Jin L, Kuncl RW et al (1996). Knockout of glutamate transporters reveals a major role for astroglial transport in excitotoxicity and clearance of glutamate. Neuron 16: 675-686.

Smith RE, Haroutunian V, Davis KL, Meador-Woodruff JH (2001). Expression of excitatory amino acid transporter transcripts in the thalamus of subjects with schizophrenia. Am J Psychiatry 158: 1393-1399.

Takasaki C, Okada R, Mitani A, Fukaya M, Yamasaki M, Fujihara Y et al (2008). Glutamate transporters regulate lesion-induced plasticity in the developing somatosensory cortex. J Neurosci 28: 4995-5006.

Torres GE, Amara SG (2007). Glutamate and monoamine transporters: new visions of form and function. Curr Opin Neurobiol 17: 304-312.

Voutsinos-Porche B, Nonvento G, Tanaka K, Steiner P, Welker E, Chatton JY et al (2003). Glial glutamate transporters mediate a functional metobolic crosstalk between neurons and astrocytes in the mouse developing cortex. Neuron 37: 275-286.

Walsh T, McClellan JM, McCarthy SE, Addington AM, Pierce SB, Cooper GM et al (2008). Rare structural variants disrupt multiple genes in neurodevelopmental pathways in schizophrenia. Science 320: 539-543.

Watase K, Hashimoto K, Kano M, Yamada K, Watanabe M, Inoue Y et al (1998). Motor discoordination and increased susceptibility to cerebellar injury in GLAST mutant mice. Eur J Neurosci 10: 976-988.

Wiedholz LM, Owens WA, Horton RE, Feyder M, Karlsson RM, Hefner $\mathrm{K}$ et al (2008). Mice lacking the AMPA GluR1 receptor exhibit striatal hyperdopaminergia and 'schizophrenia-related' behaviors. Mol Psychiatry 13: 631-640. 